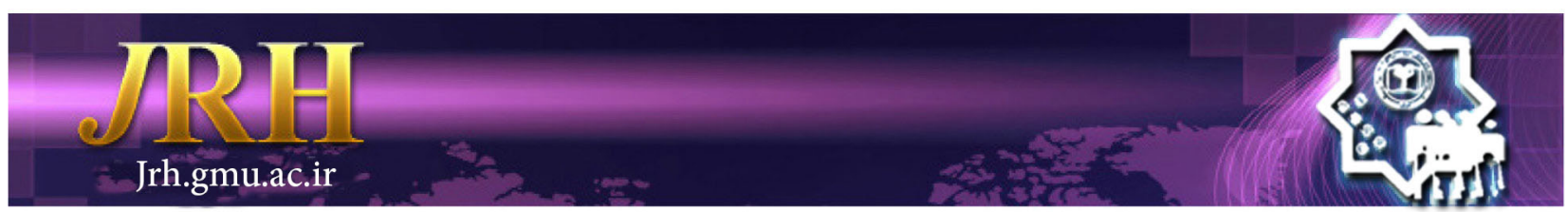

\title{
Comparison of coping strategies and emotion regulation tendencies among opium users, methadone maintenance treatment clients and normal individuals
}

Sadi Azizi $^{1}$, Alireza Maghsoudloo ${ }^{2}$, Shahab Baheshmat ${ }^{3}$

\author{
Journal of Research \& Health \\ Social Development \& Health Promotion \\ Research Center \\ Vol. 9, No. 6, Nov \& Dec 2019 \\ Pages: 533 - 543 \\ DOI: 10.32598 /jrh.9.6.533 \\ Original Article
}

1. Vice-Chairperson of the Therapeutics, Department of Mental Health and Addiction, Mazandaran University of Medical Sciences, Sari, Iran

2. Department of Psychology, School of Education, New Mexico Highlands University, Las Vegas, United States

3. Correspondence to: Department of Neuroscience and Addiction Studies, School of Advanced Technologies in Medicine, Tehran University of Medical Sciences; Iranian National Center for Addiction Studies, Tehran University of Medical Sciences, Tehran, Iran

Email: shahab.baheshmat@gmail.com

Received: 29 Sep 2016

Accepted: 25 Oct 2017

How to cite this article: Azizi S, Maghsoudloo A, Baheshmat Sh. Comparison of coping strategies and emotion regulation tendencies among opium users, methadone maintenance treatment clients and normal individuals. $\mathrm{J}$ Research \& Health2019; 9(6): 533- 543.

\begin{abstract}
Substance abuse is also related to psychological skills that affect the treatment process. Identifying the role of these skills can be useful for the development of a better intervention. This purpose of this study was to compare the coping strategies and emotion regulation profiles among opium users, methadone maintenance treatment clients, and normal individuals. The sample was selected among patients and their accompanies-relatives or friends-as attending to Sari substance abuse treatment centers in spring 2016 to start or continue professional treatment. By using convenience sampling method, participants were assigned to three groups: opium users ( $n=$ 43), methadone maintenance treatment clients $(n=45)$, and control group $(n=43)$. Measuring tools included coping inventory for stressful situations and the difficulties in emotion regulation scale for all participants in the three groups. Significant differences were observed between the control and experimental groups: compared to the control group, opium users and methadone maintenance treatment clients had more emotion regulation difficulties and more adopted avoidance and emotion-focused coping strategies. By exploring the variables associated with the onset, persistence, and severity of substance abuse, the findings suggested groundwork for further researches which could be incorporated in prevention, treatment, and rehabilitation evidence-based methods to ameliorate the rate of substance abuse and dependency and related harms.
\end{abstract}

Keywords: Adaptation, Emotions, Psychological, SubstanceRelated Disorders

\section{Introduction}

In addition to heightening the risk of physical [1] and psychological [2] diseases, substance abuse and dependency impose damage involved people (e.g., patients and their relatives), health care system [3] and the society [4]. Considering that substance abuse treatment and rehabilitation programs impose heavy financial costs to society $[5,6]$, it certainly will be worth to investigate the prevention and treatment methodologies of substance abuse and dependency [7]. As such, remarkable research has focused on assessing the risk and protective factors associated with drug use and dependency with the hope that the identification of the involved variables would lead to the development of more effective prevention and treatment programs [8]. Recent studies have focused on the interdependence 
of psychological variables such as coping strategies in response to stressors and the extent of social/familial support-and the onset and persistence of substance abuse [9]. Based on the stress-coping model of substance abuse, individuals tend to disengage from the cause of stressors and related feelings and cognitions by taking psychoactive drugs [10]. Lazarus and Folkman have defined coping as the cognitive and behavioral efforts made by an individual to manage the stressful situations [11]. Three types of coping strategies have been discussed in the researches' literature: problem-focused strategies (e.g. problem solving and seeking social support), emotion-focused strategies (e.g., anxiety and self-criticism), and avoidance strategies (e.g., wishful thinking and denial of problems). Emotion-focused and avoidance styles are considered as mal-adaptive while problem-oriented style is considered as adaptive in dealing with life stressors $[12,13]$. Previous studies have assessed the relationship between coping strategies and a range of substance abuse-related problems $[14,15]$; the findings have indicated that emotion-focused and avoidance coping strategies predict alcohol and drug use [16]. Robertson, $\mathrm{Xu}$, and Stripling [13] reported that avoidant coping strategy was associated with increased use of alcohol and other drugs among female adolescents; however, they reported no correlation between problem-focused coping strategy and alcohol or other drugs intake. Similarly, McConnell, Memetovic, and Richardson [8] found that while adaptive coping strategies were associated with lower tobacco and marijuana use, maladaptive coping strategies predicted tobacco and marijuana use among adolescents. Martindale et al [17], on the other hand, they demonstrated that the residential patients who were receiving substance abuse treatment attained improvements in coping skills after treatment. Maquez-Arrico, Benaiges and Adán [12] in their study with two groups of patients with substance use disorder -with vs. without schizophrenia- showed that compared to normal population, both groups used less of adaptive coping strategies. Van Gundy et al. [18] reported that problem-focused coping strategies were associated with lower risk of drugs-use such as marijuana among Caucasian and African-American youth; however, avoidance coping strategy was associated with increased risk of alcohol and other drugs-use among white young adults, but with lower risk of marijuana use among African-American young adults. The results of Feil and Hasking's [19] study similarly suggested that avoidant coping strategy was associated with increased alcohol use.

Closely related to coping strategies is the ability to regulate emotions while encountering stressful situations which has been reportedly associated with drug use and dependency. Developmental research has suggested that emotion regulation ability is closely connected to human wellbeing [20] which would certainly apply to substance abuse behavior [21]. Lejuez et al asserted that delayed or impaired development of cognitive, emotional, and behavioral regulation skills during childhood is essential for development, persistence, and severity of substance abuse disorder [22]. Similarly, Siegel [23] proposed that those who cannot tolerate strong negative emotions may appeal to substance abuse for relief. Emotion regulation encompasses processes responsible for monitoring, organizing, evaluating, and modifying the affective responses which underlie the ability to control impulses as the person experiences heightened emotions [24]. It also has been reported that emotion dysregulation is a critical factor in a variety of maladaptive behavioral outcomes including illicit drug use [25]. Thus, emotion regulation difficulties are among the etiological factors contributing to substance abuse [22] and comorbid disorders [26-28]. Numerous studies have shown that deficits in emotion regulation in people with substance abuse disorder were significantly higher than non-clinical healthy population [29]. Axelrod, Perepletchikova, Holtzman, and Sinha [24] showed that not only improvements in emotion regulation skills were associated with reduced drug use, but 
also those who were successful in reducing their drug use were better able to regulate emotions. Neuroscience evidence has also confirmed that individuals with substance abuse disorder have high difficulties in emotion regulation [30]. On the other hand, impairments in emotion regulation and insufficient self-control have been significantly associated with negative treatment outcomes including discontinuation of treatment and high rates of relapse [31,9]. Tull et al. [32] found that deficits in emotion regulation skills were central in increasing of substance abuse among female patients with Posttraumatic Stress Disorder (PTSD). Siegel [23] demonstrated that emotional dysregulation among children and adolescents were factors which predisposed them for later development of substance abuse disorder. Likewise Poon et al. [33] showed that more difficulties in emotion regulation among adolescents were correlated with more illicit drugs use. The findings of study by Hopwood et al. [9] also revealed that coping strategies that people adopted in response to daily stressors had determining role in their tendency to use alcohol and other drugs.

Thus, the literature suggests that maladaptive coping strategies and emotional regulation difficulties are etiological factors contributing to drug use and dependency. Yet, a comprehensive model to incorporate coping and emotion regulation tendencies has not been examined. The implication of such a model would be two-fold: theoretically, the model would stand to allocate people to substance abuser group, quitting group, or normal group; also, by determining the differential role of these variables in aforementioned groups, the model could be addressed in prevention, treatment, and rehabilitation programs; one can understand the relative importance of each one of the variables in initiation, continuation, and severity of substance use and treatment outcomes. As a social pathology, drug use and dependency undermines various aspects of human life, imposing heavy expenses to individuals and families involved as well as the society. Successful preventive strategies and sustainable treatment programs would inevitably entail the psychological aspects related to the initiation and continuation of drug use. As such, the present study addresses the applicability of specific psychological variables to treatment methods with the goal of alleviation the drug abuse problem. Hence, the aim of this paper was to compare the emotion regulation and coping strategies of opium users, methadone maintenance treatment clients, and normal individuals.

\section{Method}

This study would be classified as cross sectional research with causal-comparative data collection method and retrospective in terms of the time of data acquisition. The participants were selected from the patients and their accompanies, relatives or friends, as attending to Sari substance abuse treatment centers at North of Iran in spring 2016 to start or continue professional treatment. All participants were selected by convenience sampling method. 128 participants (all males) were assigned into three groups: opium-user $(n=43)$, methadone-treatment group $(n=45)$, and control group $(n=40)$. The opium-user group consisted of 43 opium dependents that had referred to Sari out-patient substance abuse treatment centers in spring 2016 to get professional treatment; they had not received any treatment beforehand and did not use other drugs than opium. The methadonetreatment group consisted of 45 clients who were already under methadone maintenance treatment program for at least six consecutive months at the same centers; they did not use any drug, including opium. The control group consisted of 40 normal participants with no current or past history of drug use; they were selected among the patients' relatives/friends who were accompanying them to the same centers. Furthermore, having sever psychiatric and/or physical disorders were considered as exclusion criteria in all three groups (except for substance abuse disorder in the clinical groups). The three groups of the study were matched in terms of gender (all men), age 
$(p>0.05, F=1.86)$ and educational degree $\left(p>0.05, X^{2}=166\right)$. The agreement to participate in the study was sought and obtained from all participants (ethical consideration).

The Instrument of this research were Coping Inventory of Stressful Situation (CISS) and Difficulties in Emotion Regulation Scale (DERS). Coping Inventory of Stressful Situation (CISS) developed by Endler and Parker, the CISS measures three major types of coping strategies: problem-focused, emotion-focused and avoidance coping strategy. Respondents are responded to 48 items on 5-point Likerttype rating scale ranging from (1) "Not at all" to (5) "Very much." Respondents are asked to "indicate how much you engage in these types of activities when you encounter a difficult, stressful, or upsetting situation." The multi-dimensional approach to the assessment of coping with stressful situations provides great precision in predicting preferred coping strategies. Endler and Parker assessed the validity of this test for both genders through Cronbach's Alpha and reported it as 0.90 and 0.92 in problem-focused style, 0.85 and 0.82 in emotion-focused style, and 0.82 and 0.85 in avoidance coping strategy for females and males respectively. Jaffarnejad [34] reported the Cronbach's coefficient alpha as 09.83 for problem-focused, 0.80 for emotion-focused, and 0.72 for avoidance coping strategy. For the present study, the Cronbach's alpha, as a measure of internal consistency of this scale, was assessed and obtained as 0.73 for problemfocused, 0.76 for emotion-focused, and 0.68 for avoidance copying style.

Difficulties in Emotion Regulation Scale (DERS) was another instrument for gathering data. It developed by Gratz and Roemer in 2001, DERS is brief, 36-item, self-report questionnaire to assess multiple aspects of emotion dysregulation. The measure yields a total score as well as scores on six sub-scales:

1) Non-acceptance of emotional responses (Non-acceptance), 2) Difficulties engaging in goal-directed behavior (Goals), 3) Impulse control difficulties (Impulse), 4) Lack of emotional awareness (Awareness), 5) Limited access to emotion regulation strategies (Strategies), 6) Lack of emotional clarity (Clarity). Items of this questionnaires use 5 -point Likert scales by asking respondents to rate the statements $(1=$ almost never, $6=$ almost always). Higher scores stand for more difficulty in emotional regulation. In order to assess the reliability of the questionnaire, Gratz and Roemer [35] assessed the internal consistency by the Cronbach's coefficient alpha which was adequately obtained for the total scale $(a=0.93)$ and for each of the sub-scales $(\alpha>0.80)$. In Amininan's study [36] the validity of the scale was established by assessing Cronbach's Alpha as 0.86 and split-half method as 0.80 . The Cronbach's alpha was assessed for the sub-scales of the study as well and obtained as 0.81 for Nonacceptance, 0.79 for Goals, 0.73 for Impulse, 0.71 for Awareness, 0.82 for Strategies, and 0.63 for Clarity sub-scale.

Data collection plans were employed in careful method: the respondents were given to questionnaires by the researcher and were asked to complete them in researcher presence. We excluded the questionnaires which had been filling-out hastily, as considered as such by the attentive researcher as well as the ones some of the questions of which had been left blank. we conducted descriptive and inferential statistical analyses: mean and standard deviation for obtaining the measures of central tendency and variability, Chi-square and one-way analysis of variance (ANOVA) for equivalence testing, and multivariate analysis of variance (MANOVA) for hypothesis testing by using SPSS- 21 . Differences with a probability of less than 0.05 were considered to be statistically significant.

\section{Results}

All of participants were male, age ranging from 21-38 years old. The mean age for opium-user group was 31.07 ( $\mathrm{SD}=3.54$ ), for methadone treatment group was 29.16 $(\mathrm{SD}=4.49)$, and for the control group was 29.32 ( $\mathrm{SD}=3.89$ ). Most participants had high school diploma (Table 1). The demographic 
questionnaires which had developed by the researcher, provided the age and educational level of participants, which were used for equivalence testing: the results indicated that the three groups were equivalent in terms of age and educational level, since there were neither significant mean age differences among the three groups, as measured by ANOVA, nor significant differences for educational level, as measured by Chi-square. Table 2 summarized the mean and standard deviation of the three groups for all variables of the study.

A Multivariable Analysis of Variance (MANOVA) was employed to compare the means of the three groups for each of coping strategies and the emotional regulation styles.

Table 1 Demographic information of study samples based on age and education levels

\begin{tabular}{|c|c|c|c|c|c|c|c|c|}
\hline \multirow{3}{*}{ Group } & \multirow{2}{*}{\multicolumn{2}{|c|}{ Age }} & \multicolumn{6}{|c|}{ Education levels } \\
\hline & & & \multicolumn{2}{|c|}{ Some high school } & \multicolumn{2}{|c|}{ High school diploma } & \multicolumn{2}{|c|}{ University degree } \\
\hline & $\mathrm{M}$ & SD & $f_{i}$ & $\mathrm{P}$ & $\mathrm{f}_{\mathrm{i}}$ & $\mathrm{P}$ & $f_{i}$ & $\mathrm{P}$ \\
\hline Health & 29.32 & 3.89 & 6 & $\% 15$ & 30 & $\% 75$ & 4 & $10 \%$ \\
\hline MMT & 29.16 & 4.49 & 6 & $\% 13.3$ & 35 & $\% 77.8$ & 4 & $8.9 \%$ \\
\hline Opium & 31.07 & 3.54 & 5 & $\% 11.6$ & 33 & $\% 76.7$ & 5 & $11.6 \%$ \\
\hline
\end{tabular}

Table 2 Mean and standard deviation of coping and emotion regulation tendencies in three groups

\begin{tabular}{lcccccc}
\hline \multirow{2}{*}{ Variables } & \multicolumn{2}{c}{ Opium users } & \multicolumn{2}{c}{ MMT Clients } & \multicolumn{2}{c}{ Normal individuals } \\
\cline { 2 - 6 } & $\mathrm{M}$ & $\mathrm{SD}$ & $\mathrm{M}$ & $\mathrm{SD}$ & $\mathrm{M}$ & $\mathrm{SD}$ \\
\hline Problem-focused coping & 45.2 & 5.93 & 46.02 & 7.47 & 51.92 & 6.94 \\
Emotion-focused coping & 55.91 & 5.75 & 52.58 & 7.08 & 49.02 & 6.68 \\
Avoidant-focused coping & 54.79 & 5.60 & 52.33 & 7.03 & 45.82 & 6.82 \\
Non-acceptance & 20.60 & 2.98 & 20 & 3.52 & 16.22 & 3.29 \\
Goals & 18.72 & 3.60 & 19.33 & 3.51 & 17.12 & 3.93 \\
Impulsivity & 18.72 & 2.74 & 19.47 & 3.29 & 16.98 & 3.53 \\
Awareness & 19.86 & 2.40 & 19.38 & 2.61 & 17.58 & 3.39 \\
Strategies & 22.44 & 2.59 & 21.84 & 3.52 & 17.32 & 3.66 \\
Clarity & 21.28 & 2.99 & 20.73 & 3.89 & 17.40 & 3.79 \\
\hline
\end{tabular}

The assumptions to use the MANOVA were reviewed (Table 3 ) and also were established including normal distribution of data which was tested by the Shapiro-Wilk test ( $p>0.05)$.
According to the Levene's test which was employed to assess the equality of variances for the variables in three groups, also the assumption of homogeneity of variance

Table 3 Checking the assumptions of MANOVA

\begin{tabular}{lcccccc}
\hline & & & & \multicolumn{2}{c}{ Shapiro - Wilk } & \multicolumn{2}{c}{ Levene's Test } \\
\cline { 3 - 6 } Variables & Skewness & Kurtosis & Z & Sig. & F & Sig. \\
\hline Problem-focused coping & 0.080 & -0.419 & 0.987 & 0.264 & 1.209 & 0.302 \\
Emotion-focused coping & -0.117 & -0.215 & 0.992 & 0.638 & 0.974 & 0.380 \\
Avoidant-focused coping & -0.235 & -0.344 & 0.984 & 0.150 & 1.107 & 0.334 \\
Non-acceptance & -0.196 & -0.135 & 0.984 & 0.145 & 1 & 0.371 \\
Goals & -0.002 & -0.265 & 0.987 & 0.268 & 0.410 & 0.664 \\
Impulsivity & -0.088 & -0.369 & 0.985 & 0.156 & 2.100 & 0.127 \\
Awareness & -0.339 & 0.075 & 0.980 & 0.057 & 2.949 & 0.056 \\
Strategies & -0.042 & 0.281 & 0.985 & 0.181 & 0.650 & 0.524 \\
Clarity & -0.250 & 0.091 & 0.985 & 0.158 & 2.257 & 0.109 \\
\hline
\end{tabular}


was established $(\mathrm{p}>0.05)$. Box'M was used to determine whether covariance matrices were equal and the Box's $M$ test indicated that the observed covariance matrices of the dependent variables were equal across the independent variables (the groups), so the assumption of Homogeneity of Covariance Matrices was met $(\mathrm{p}>0.05)$.

Since the assumptions to use the MANOVA were established, we used this test to check the study's hypotheses to compare the coping strategies in the three groups of the study. The data show that by significant levels of all tests we can use MANOVA. The result of multivariate Wilk's Lambda test was significant $(\mathrm{F}=16.60, \mathrm{p}<0.001)$ which indicating that there was between-group differences in terms of coping strategies.

However these differences neither specify which groups were different, nor determine which variables significantly differed from the rest. MANOVA and Tukey test showed that the mean scores of the opium users and the methadone treatment clients were significantly higher in avoidant and emotionfocused coping strategies than those of the participants in the contro 1 group while the mean difference for the aforementioned coping strategies was not significant between the opium users group and the methadone treatment clients group. In the problemfocused coping strategy, the mean score of the normal group was high in avoidant or the emotion-focused coping strategies (Table 4).

Table 4 MANOVA and Tukey test for coping strategies

\begin{tabular}{|c|c|c|c|c|c|c|c|c|c|c|}
\hline Variable & $\mathrm{df}$ & MS & $\mathrm{F}$ & Sig. & $\mathrm{Eta}^{2}$ & Reference & Comparison & $\mathrm{MD}$ & Std.Error & Sig. \\
\hline \multirow{6}{*}{$\begin{array}{l}00 \\
\Xi 0 \\
0 \\
0 \\
0 \\
0 \\
0 \\
0 \\
0 \\
0 \\
1 \\
0 \\
0 \\
0 \\
0 \\
0 \\
0\end{array}$} & \multirow{6}{*}{2} & \multirow{6}{*}{440.06} & \multirow{6}{*}{9.11} & \multirow{6}{*}{0.000} & \multirow{6}{*}{0.127} & \multirow{2}{*}{ Health } & MMT & 4.96 & 1.508 & 0.004 \\
\hline & & & & & & & Opium & 6.11 & 1.517 & 0.001 \\
\hline & & & & & & \multirow[b]{2}{*}{ MMT } & Health & -4.96 & 1.508 & 0.004 \\
\hline & & & & & & & Opium & 1.15 & 1.490 & 0.720 \\
\hline & & & & & & \multirow{2}{*}{ Opium } & Health & -6.11 & 1.517 & 0.001 \\
\hline & & & & & & & MMT & -1.15 & 1.490 & 0.720 \\
\hline \multirow{6}{*}{$\begin{array}{l}00 \\
.0 \\
0 \\
0 \\
0 \\
0 \\
0 \\
0 \\
0 \\
0 \\
0 \\
1 \\
0.0 \\
0 \\
0 \\
0 \\
1\end{array}$} & \multirow{6}{*}{2} & \multirow{6}{*}{557.10} & \multirow{6}{*}{13.37} & \multirow{6}{*}{0.000} & \multirow{6}{*}{0.176} & \multirow{2}{*}{ Health } & MMT & -4.34 & 1.401 & 0.007 \\
\hline & & & & & & & Opium & -7.25 & 1.409 & 0.001 \\
\hline & & & & & & \multirow{2}{*}{ MMT } & Health & 4.34 & 1.401 & 0.007 \\
\hline & & & & & & & Opium & -2.91 & 1.384 & 0.094 \\
\hline & & & & & & \multirow{2}{*}{ Opium } & Health & 7.25 & 1.409 & 0.001 \\
\hline & & & & & & & MMT & 2.91 & 1.384 & 0.094 \\
\hline \multirow{6}{*}{ 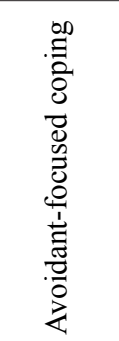 } & \multirow{6}{*}{2} & \multirow{6}{*}{987.21} & \multirow{6}{*}{24.18} & \multirow{6}{*}{0.000} & \multirow{6}{*}{0.279} & \multirow{2}{*}{ Health } & MMT & -7.21 & 1.387 & 0.001 \\
\hline & & & & & & & Opium & -9.25 & 1.395 & 0.001 \\
\hline & & & & & & \multirow{2}{*}{ MMT } & Health & 7.21 & 1.387 & 0.001 \\
\hline & & & & & & & Opium & -2.04 & 1.370 & 0.299 \\
\hline & & & & & & \multirow{2}{*}{ Opium } & Health & 9.25 & 1.395 & 0.001 \\
\hline & & & & & & & MMT & 2.04 & 1.370 & 0.299 \\
\hline
\end{tabular}

MANOVA and Tukey test were used to compare mean scores of three groups in terms of emotion regulation difficulties (Table 5). The results indicated that the opium users and methadone treatment clients had higher scores in emotional regulation difficulties and its subscales in comparison with normal peers, but no significant difference was observed between the opium users and methadone treatment groups. Also, the result of multivariate Wilk's Lambda test $(\mathrm{F}=6.21, \mathrm{p}<0.001)$ indicated that there was significant differences among the groups of the study at least in one of the subscales of emotional regulation difficulties. 
Table 5 MANOVA and Tukey test for emotion regulation difficulties

\begin{tabular}{|c|c|c|c|c|c|c|c|c|c|c|}
\hline Variable & $\mathrm{df}$ & MS & $\mathrm{F}$ & Sig. & $\mathrm{Eta}^{2}$ & Reference & Comparison & MD & Std.Error & Sig. \\
\hline \multirow{6}{*}{ 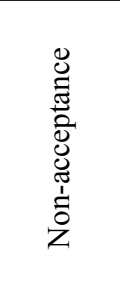 } & \multirow{6}{*}{2} & \multirow{6}{*}{231.8} & \multirow{6}{*}{21.57} & \multirow{6}{*}{0.000} & \multirow{6}{*}{0.257} & \multirow{2}{*}{ Health } & MMT & -3.78 & 0.712 & 0.001 \\
\hline & & & & & & & Opium & -4.38 & 0.720 & 0.001 \\
\hline & & & & & & \multirow{2}{*}{ MMT } & Health & 3.78 & 0.712 & 0.001 \\
\hline & & & & & & & Opium & -0.60 & 0.699 & 0.633 \\
\hline & & & & & & \multirow{2}{*}{ Opium } & Health & 4.38 & 0.720 & 0.001 \\
\hline & & & & & & & MMT & 0.60 & 0.699 & 0.633 \\
\hline \multirow{6}{*}{$\begin{array}{l}\text { ñ } \\
\text { ரू } \\
0\end{array}$} & \multirow{6}{*}{2} & \multirow{6}{*}{54.23} & \multirow{6}{*}{4} & \multirow{6}{*}{0.021} & \multirow{6}{*}{0.060} & \multirow{2}{*}{ Health } & MMT & -2.21 & 0.800 & 0.018 \\
\hline & & & & & & & Opium & -1.60 & 0.808 & 0.123 \\
\hline & & & & & & \multirow{2}{*}{ MMT } & Health & 2.21 & 0.800 & 0.018 \\
\hline & & & & & & & Opium & 0.61 & 0.785 & 0.716 \\
\hline & & & & & & \multirow{2}{*}{ Opium } & Health & 1.60 & 0.808 & 0.123 \\
\hline & & & & & & & MMT & -0.61 & 0.785 & 0.716 \\
\hline \multirow{6}{*}{$\begin{array}{l}\frac{0}{0} \\
\vec{\Xi} \\
\text { : }\end{array}$} & \multirow{6}{*}{2} & \multirow{6}{*}{68.33} & \multirow{6}{*}{6.66} & \multirow{6}{*}{0.002} & \multirow{6}{*}{0.096} & \multirow{2}{*}{ Health } & MMT & -2.49 & 0.696 & 0.001 \\
\hline & & & & & & & Opium & -1.75 & 0.703 & 0.038 \\
\hline & & & & & & ד & Health & 2.49 & 0.696 & 0.001 \\
\hline & & & & & & МIVI & Opium & 0.75 & 0.683 & 0.521 \\
\hline & & & & & & Oni & Health & 1.75 & 0.703 & 0.038 \\
\hline & & & & & & Opium & MMT & -0.75 & 0.683 & 0.521 \\
\hline & & & & & & Holtt & MMT & -1.80 & 0.613 & 0.011 \\
\hline & & & & & & Hedaltn & Opium & -2.29 & 0.619 & 0.001 \\
\hline$\stackrel{0}{0}$ & 2 & 5070 & 751 & $00 \cap 1$ & 0107 & M & Health & 1.80 & 0.613 & 0.011 \\
\hline 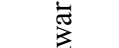 & 2 & 59.10 & 1.51 & 0.001 & 0.101 & MIMI & Opium & -0.48 & 0.601 & 0.702 \\
\hline & & & & & & Oninim & Health & 2.29 & 0.715 & 0.001 \\
\hline & & & & & & Opium & MMT & 0.48 & 0.723 & 0.702 \\
\hline & & & & & & Hoolth & MMT & -4.52 & 0.715 & 0.001 \\
\hline & & & & & & Healun & Opium & -5.12 & 0.702 & 0.001 \\
\hline$\frac{0}{60}$ & 2 & 2027 & 2076 & $00 \Omega 0$ & 0222 & M T T & Health & 4.52 & 0.723 & 0.001 \\
\hline 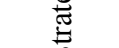 & 2 & 322.22 & 29.10 & 0.000 & 0.323 & MINII & Opium & -0.60 & 0.702 & 0.672 \\
\hline & & & & & & Onium & Health & 5.12 & 0.778 & 0.000 \\
\hline & & & & & & Opium & MMT & 0.60 & 0.787 & 0.672 \\
\hline & & & & & & Hoolth & MMT & -3.33 & 0.778 & 0.001 \\
\hline & & & & & & Hedaltn & Opium & -3.88 & 0.764 & 0.001 \\
\hline 坣 & 2 & 18147 & 1415 & $00 \Omega 0$ & 0185 & MMT & Health & 3.33 & 0.787 & 0.001 \\
\hline$\frac{\pi}{U}$ & 2 & $181.4 /$ & 14.15 & 0.000 & 0.185 & MIVII & Opium & -0.55 & 0.764 & 0.755 \\
\hline & & & & & & Onium & Health & 3.88 & 0.787 & 0.001 \\
\hline & & & & & & Upium & MMT & 0.55 & 0.764 & 0.755 \\
\hline
\end{tabular}

\section{Discussion}

The purpose of the present study was to compare the coping strategies and emotion regulation difficulties among opium users, methadone maintenance treatment clients, and normal individuals. The results revealed significant between-groups differences in coping strategies; that is, opium users and those under methadone maintenance treatment mostly used emotion-focused and avoidant coping Strategies compared to participants in control group who generally adopted problem-focused coping strategies in response to stressors. This finding is consistent with results of McConnell et al [8], Robertson and Stripling [13] and Van Gundy et al [18]. According to Endler and Parker's model the emotion-focused and avoidant coping strategies are considered as maladaptive 
styles in facing stressful life events; further studies $[8,10]$ have indicated that people with maladaptive coping strategies might turn to substance abuse to deal with stressful and negative events. Robertson, Qiu, and Stripling [13] confirmed that more exposure to negative life events were associated with more consumption of drugs. To further explain the relationship between emotion-oriented and avoidance coping tendencies and substance abuse, it could be argued that people with aforementioned coping strategies have poorer social relationships and communication skills and, less seek social support when encountered with stressful situations. In contrast to Murphy and Khantzian's [37] study showed that coping strategies were improved after treatment, in this study no differences were observed between those who were seeking the treatment for the first time and those who had been receiving it for some period in time; that is, participants in methadone treatment group also adopted emotion-focused and avoidance coping tendencies in response to stressors. Arguably, the improvement in coping skills as reported by Murphy and Khantzian [37], must be observed in longitudinal studies; that is because more time would be needed over the course of treatment for methadone treatment receivers to make adjustments in their coping strategies. In other words the participants in methadonetreatment group in this study did not have time enough to modify their coping strategies by incorporating problem-oriented skills.

The results of MANOVA and Tukey test indicated significant between-group differences in terms of difficulties in regulating emotions as indicated by the DERS total score and its subscale scores including Non-acceptance, Goals, and Impulse, Awareness, Strategies, and Clarity. These results are partly consistent with findings of Tull et al [32], Poon et al [33], Siegel [23] and Hopwood et al [9]. The association between difficulties in emotion regulation and difficulties in seeking social support would help explain the observed differences. The non-acceptance of emotional responses refers to non-accepting reactions to one's negative emotional experiences that is because an individual lacks the ability to accept his/her negative emotional state and, therefore, would experience secondary negative emotions such as distress, shame, or guilt [35]. The present study showed that the opium users and those in methadone maintenance treatment program tend to have difficulties in accepting their emotional responses; it could be reasoned, thus, that these people tend to use drugs as a remedy for their secondary negative emotional experiences. In impulsivity dimension, the score of normal participants were significantly lower than the score of two other groups. The impulsivity dimension refers to the ability to control one's behaviors and refrain from inappropriate, undesired behavioral responses to negative emotional states [35]. Accordingly, drug abuse as an impulsive behavior could be the result of emotional dysregulation and impulse control difficulties. Another finding of this study was the significant differences between the normal, normal individuals and current or past drug users in the emotional awareness and emotional clarity factors. Emotional awareness refers to the ability to attend to and acknowledge one's emotional states while emotional clarity accounts for the ability to discern, understand, and label the emotions, as they occur, and to distinguish them from other emotions [35]. It seems that having difficulty in emotional awareness and/or emotional clarity would advance to more psychological distress in the face of stressful events than not. Hence, drug use could be viewed as a mean to get relief from experienced psychological distress. Likewise, there was significant difference between normal participants and the other two groups in the emotional regulation dimension. Being unable to regulate negative emotions, those who lack emotion regulation skills, tend to appeal to drug consumption as a way to alleviate negative emotions. Accordingly, those who lack proper social support would turn to substance use as a strategy to cope with their problems during stressors. People who lack proper emotion 
regulation skills may be more likely than others to engage in high-risk behaviors as a means to relieve negative emotions. Thus, difficulties in emotion regulation can heighten the risk of engagement in high risk behaviors such as substance abuse. It can further be argued that similar to maladaptive coping strategies, difficulties in emotion regulation also would make it less likely for one to successfully seek and obtain social support in the face of stressful events. In turn, lacking of proper social support would lead one to substance abuse as a strategy to cope with problems when faced with stressors. Taking into consideration the research data indicating that drug users utilize less effective coping strategies compared to normal population in the face of life stressors $[14,15,19,22,33]$ along with the fact that coping strategies and emotional regulation tendencies could change over the course of time specially by receiving appropriate education and training [17,24], that receiving the coping and emotional regulation skills training would effectively help the population at the risk of drug intake both appealing to drug consumption (initiation, severity, continuation, and relapse) as a mean to reveal from cognitions and emotions associated with negative life events. The identification of the adolescent population at risk in schools could be the starting point in addressing the skill training programs as a preventive strategy which could be extended to enhance the treatment approach among older population as well to incorporate coping skills training in conjunction with pharmacological treatment and social/familial support.

The limitation of this study was the use of convenience sampling method so it is suggested that more representative sampling techniques can be used in future studies.

\section{Conclusion}

The findings of this study have theoretical and practical implications; theoretically, these results confirm the hypotheses regarding the relationship between coping and emotion regulation tendencies and substance abuse. Practically, the findings can be addressed in development and evaluation of evidencebased educational, interventional, and therapeutic programs.

\section{Acknowledgements}

The authors of this study appreciate the participants and all involved people for their kind cooperation.

This study was approved by Mazandaran University of Medical Sciences through the letter-number D-D-4-7198 at 2019.10.30.

\section{Authors' contributions}

Study design: SBJ, AM, SA

Data collection and analysis: SBJ

Manuscript preparation: SBJ, AM

All authors have read and approved the final version.

\section{Conflict of Interest}

"The authors declare that they have no competing interests."

\section{Funding}

The author (s) received no financial support for the research, authorship and/or publication of this article.

\section{Availability of data and materials}

The datasets used and/or analyzed during this study are available from the corresponding author on reasonable request.

\section{References}

1- Tremain D, Freund M, Wye P, et al. Provision of Chronic Disease Preventive Care in Community Substance Use Services: Client and Clinician Report. $J$ Subst Abuse Treat2016; 30(68): 24-30.

2- Agrawal A, Budney AJ, Lynskey MT. The cooccurring use and misuse of cannabis and tobacco: a review. Addiction2012; 107(7): 1221-33.

3- Peiper NC, Ridenour TA, Hochwalt B, CoyneBeasley T. Overview on prevalence and recent trends in adolescent substance use and abuse. Child Adolesc Psychiatr Clin N Am2016; 25(3): 349-65.

4- Klein JW. Pharmacotherapy for substance use disorders. Med Clin North Am2016; 100(4): 891-910.

5- Harrop E, Catalano RF. Evidence-based prevention for adolescent substance use. Child Adolesc Psychiatr 
Clin N Am2016; 25(3): 387-410.

6- Hansen RN, Oster G, Edelsberg J, Woody GE, Sullivan $\mathrm{SD}$. Economic costs of nonmedical use of prescription opioids. Clin J Pain2011; 27(3): 194-202.

7- Denney AS, Connor DP. Serious juvenile offenders who have experienced emerging adulthood: Substance use and recidivism. Child Youth Serv Rev2016; 67: 11-19.

8- McConnell MM, Memetovic J, Richardson CG. Coping style and substance use intention and behavior patterns in a cohort of BC adolescents. Addict Behav2014; 39(10): 2015-8.

9- Hopwood CJ, Schade N, Matusiewicz A, Daughters $\mathrm{SB}$, Lejuez CW. Emotion regulation promotes persistence in a residential substance abuse treatment. Subst Use Misuse2015; 50(2): 251-6.

10- Floyd LJ, Hedden S, Lawson A, Salama C, Moleko AG, Latimer W. The association between poly-substance use, coping, and sex trade among black South African substance users. Subst Use Misuse2010; 45: 1971-87.

11- Kronenberg LM, Goossens PJ, Van Busschbach J, Achterberg T, Brink W. Coping styles in substance use disorder (SUD) patients with and without co-occurring attention deficit-hyperactivity disorder (ADHD) or autism spectrum disorder (ASD). BMC Psychiatry2015; 15(1): 159-67.

12- Marquez-Arrico JE, Benaiges I, Adan A. Strategies to cope with treatment in substance use disorder male patients with and without schizophrenia. Psychiatry Res2015; 228(3): 752-9.

13- Robertson AA, Xu X, Stripling A. Adverse events and substance use among female adolescent offenders: effects of coping and family support. Subst Use Misuse2010; 45(3): 451-72.

14- Hasking PA, Oei T. The complexity of drinking: Interactions between the cognitive and behavioral determinants of alcohol consumption. Addict Res Theory2004; 12(5): 469-88.

15- Sánchez M, Rice E, Stein J, Milburn NG, RotheramBorus MJ. Acculturation, coping styles, and health risk behaviors among HIV positive Latinas. AIDS Behav2010; 14(2): 401-9.

16-Eitle TM, Eitle D. Race, coping strategies, and substance use behaviors: A preliminary analysis examining White and American Indian adolescents. Subst Use Misuse2014; 49(3): 315-25.

17- Martindale SL, Sejud LR, Giardina A, McGowan S, Dolan SL. Changes in coping strategies over time in a residential substance use disorder treatment population: a preliminary assessment. Alcohol Treat Q2013; 31(4): 484-94. 18- Van Gundy KT, Howerton-Orcutt A, Mills ML. Race, coping style, and substance use disorder among nonhispanic African American and white young adults in South Florida. Subst Use Misuse2015; 50(11): 1459-69.

19- Feil J, Hasking P. The relationship between personality, coping strategies and alcohol use. Addict Res Theory2008; 16(5): 526-37.

20- Philippot P, Feldman RS. The regulation of emotion. New York: Psychology press; 2013.

21- Dragan M. Difficulties in emotion regulation and problem drinking in young women: The mediating effect of metacognitions about alcohol use. Addict Behav2015; 48: $30-35$.

22- Hulvershorn LA, Finn P, Hummer TA, et al. Cortical activation deficits during facial emotion processing in youth at high risk for the development of substance use disorders. Drug Alcohol Depend2013; 131(3): 230-7.

23- Siegel JP. Emotional regulation in adolescent substance use disorders: Rethinking risk. J Child Adolesc Subst Abuse2015; 24(2): 67-79.

24- Axelrod SR, Perepletchikova F, Holtzman K, Sinha

R. Emotion regulation and substance use frequency in women with substance dependence and borderline personality disorder receiving dialectical behavior therapy. Am J Drug Alcohol Abuse2011; 37(1): 37-42.

25- Galang JN, Babson KA, Boden MT, Bonn-Miller MO. Difficulties in emotion regulation are associated with panic symptom severity following a quit attempt among cannabis dependent veterans. Anxiety Stress Coping2015; 28(2): 192-204.

26- Shadur JM, Lejuez CW. Adolescent substance use and comorbid psychopathology: emotion regulation deficits as a transdiagnostic risk factor. Curr Addict Rep2015; 2(4): 354-63.

27- Cheetham A, Allen NB, Whittle S, Simmons J, Yücel M, Lubman DI. Volumetric differences in the anterior cingulate cortex prospectively predict alcohol-related problems in adolescence. Psychopharmacology2014; 231(8): 1731-42.

28- Wilens TE, Martelon M, Anderson JP, ShelleyAbrahamson R, Biederman J. Difficulties in emotional regulation and substance use disorders: A controlled family study of bipolar adolescents. Drug Alcohol Depend2013; 132(1-2): 114-21.

29- Price CJ, Herting JR. Changes in post traumatic stress symptoms among women in substance use disorder treatment: The mediating role of bodily dissociation and emotion regulation. Subst Abuse2013; 7: 147-53.

30- Albein-Urios N, Verdejo-Román J, Soriano-Mas C, Asensio S, Martínez-González JM, Verdejo-García A. Cocaine users with comorbid Cluster B personality disorders show dysfunctional brain activation and connectivity in the emotional regulation networks during negative emotion maintenance and reappraisal. European Eur Neuropsychopharmacol2013; 23(12): 1698-707.

31- Miller PM, Ball SA, Bates ME, et al. Comprehensive addictive behaviors and disorders, Vol 1: Principles of addiction. San Diego, CA, US: Elsevier Academic press; 2013. pp: 203-212. 
32- Tull MT, Bardeen JR, DiLillo D, Messman-Moore T, Gratz KL. A prospective investigation of emotion dysregulation as a moderator of the relation between posttraumatic stress symptoms and substance use severity. J Anxiety Disord2015; 29: 52-60.

33- Poon JA, Turpyn CC, Hansen A, et al. Adolescent substance use \& psychopathology: Interactive effects of cortisol reactivity and emotion regulation. Cognit Ther Res2016; 40(3): 368-80.

34- Jafarnezhad P, Farzad V, Moradi AR, Shokri O. Relationship between big five factor, coping style and mental health in graduate students of Tarbiyat Moallem University. Journal of Psychology and Educational Science2005; 35(1): 51-74.
35- Gratz KL, Roemer L. Multidimensional assessment of emotion regulation and dysregulation: Development, factor structure, and initial validation of the difficulties in emotion regulation scale. $J$ Psychopathol Behav Assess 2004; 26(1): 41-54.

36- Mazaheri M, Manshaee G. Difficulties in emotion regulation in IBS patients and normal people- with control emotional problems. Journal of Guilan University of Medical Sciences2016; 25(98) :70-9.

37- Murphy S, Khantzian E. Addiction as a "selfmedication" disorder: application of ego psychology to the treatment of substance abuse. In: Washton A, ed. Psychotherapy and substance abuse: a practitioner's Handbook. London: Guilford press; 1995. pp: 161-75.

Copyright $\odot 2016$ ASP Ins. This open-access article is published under the terms of the Creative Commons Attribution-NonCommercial 4.0 International License which permits Share (copy and redistribute the material in any medium or format) and Adapt (remix, transform, and build upon the material) under the Attribution-NonCommercial terms. 